\title{
Apresentação do Dossiê "Conexões Transversais entre a Antropologia da Ciência e a Etnologia"
}

Presenting the Special issue "Transversal Connections between Anthropology of Science and Ethnology"

Joana Cabral, Felipe Süssekind e Guilherme Sá

\section{(2) OpenEdition}

\section{Edição electrónica}

URL: http://journals.openedition.org/aa/6567

DOI: $10.4000 / a a .6567$

ISSN: 2357-738X

\section{Editora}

Programa de Pós-Graduação em Antropologia Social (UnB)

\section{Refêrencia eletrónica}

Joana Cabral, Felipe Süssekind e Guilherme Sá, «Apresentação do Dossiê "Conexões Transversais entre a Antropologia da Ciência e a Etnologia"», Anuário Antropológico [Online], v.45 n.3 | 2020, posto online no dia , consultado o 27 abril 2021. URL: http://journals.openedition.org/aa/6567 ; DOI: https:// doi.org/10.4000/aa.6567

\section{(c) (i) (9)}

Anuário Antropológico is licensed under a Creative Commons Atribuição-Uso Não-Comercial-Proibição de realização de Obras Derivadas 4.0 International. 
dossiê

. $45 \cdot n .3$ - setembro-dezembro - 2020.3 


\section{dossiê}

Apresentação do Dossiê "Conexões transversais entre a Antropologia da Ciência e a Etnologia" Joana Cabral de Oliveira, Felipe Sussekind e Guilherme Sá

Transformações do boto na Amazônia: relações transversais entre campos de conhecimento Kauã Vasconcelos e Felipe Süssekind

Humanos, sempre-vivas e outros-que-não-humanos: coletando e compondo o mundo comum no Espinhaço Meridional-MG Bethânia Gabrielle dos Santos e Fátima Teresa Braga Branquinho

Transformações antropogênicas, mito, música e os coletivos xamanísticos Ka'apor: experimentações preliminares a caminho de uma etnomusicologia de multiespécies Hugo Maximino Camarinha

"Aquela serra é o xapono deles": sobre encontros, ontologias e equivocidades no Projeto Yaripo Leon Terci Goulart

As festas do milho krahô: cantando sementes e semeando cantos Ana Gabriela Morim Lima, Creuza Prumkwyj Krahô e Veronica Aldé

kubẽ-kà kumrenx: Vestidos e gênero entre os Mẽbêngôkre Julia Sá Earp

Concepções e conhecimentos quilombolas e as hipóteses científicas sobre a criação e a reprodução das florestas de castanhais-Alto Trombetas, Oriximiná-PA Igor Scaramuzzi

Vidas e (re)existências no território quilombola da Costa da Lagoa Eleandra Raquel da Silva Koch e Vanessa Flores dos Santos 


\section{Apresentação do Dossiê: Conexões Transversais entre a Antropologia da Ciência e a Etnologia}

Presenting the Special issue:

Transversal Connections between Anthropology of Science and Ethnology

DOI: https://doi.org/10.4000/aa.6567

Joana Cabral • Universidade Estadual de Campinas - Brasil

Professora do Departamento de Antropologia da Unicamp. Doutora em Antropologia pela USP, realizou suas pesquisas junto aos Wajãpi, tendo atuação indigenista junto a esse e outros povos indígenas nas áreas de educação, saúde e questões ambientais. Também realizou pesquisas de antropologia da ciência com botânicos e em pesquisa colaborativa sobre leishmaniose.

Felipe Süssekind • Pontifícia Universidade Católica do Rio de Janeiro - Brasil Professor do Departamento de Ciências Sociais da Pontifícia Universidade Católica do Rio de Janeiro (PUC-Rio), onde coordena o Laboratório de Estudos Socioambientais. Doutor em Antropologia Social pelo Museu Nacional - UFRJ.

\section{Guilherme Sá • Universidade de Brasília - Brasil}




\section{Da Antropologia da Ciência à Etnologia Ameríndia}

Ao propormos uma reflexão sobre as transversalidades entre etnologia e antropologia da ciência, não pretendemos realizar uma genealogia, um levantamento extensivo ou encontrar um ponto zero desse encontro. Nosso esforço é no sentido de apontar uma narrativa possível sobre essa trajetória epistêmica que reúne os artigos que compõem este dossiê.

Não seria exagero dizer que parte significativa daquilo que - a partir do início dos anos 2000 - se consolidou como o campo da Antropologia da Ciência no Brasil teve origem em um diálogo transversal entre pesquisadores "das ciências" e da "etnologia ameríndia". Esta aproximação evidenciava o interesse, até hoje legítimo, de estabelecer as bases para um novo campo de pesquisa antropológico no país, levando em consideração não as divisões em subáreas delimitadas por objetos de estudo, mas antes uma forma singular de pensar e fazer antropologia. Para contar um pouco desta trajetória - diferente daquela transcorrida em países que priorizaram originalmente relações com a chamada grande área dos estudos sociais da ciência e da tecnologia (STS), ou mesmo com outras subáreas como as antropologias urbanas, do gênero e da saúde/doença -, é fundamental entender por onde passaram os interesses formativos de algumas das primeiras pesquisas em antropologia da ciência no Brasil que conduziram aos encontros com a etnologia (Sá, 2006; Walford, 2008; Marras, 2009; Calheiros, 2009; Süssekind, 2010; Cabral de Oliveira, 2012; Estorniolo, 2012).

Esses primeiros diálogos buscavam levar em consideração múltiplas agências, formas de associação e modos de existência, bem como partilhavam o entendimento de que o cerne epistemológico da antropologia estaria na sua capacidade de se (auto)transformar a partir do encontro entre dois possíveis projetos de conhecimento complementares: o do antropólogo e o de seus interlocutores. À medida em que se distanciava do paradigma antropológico representacionalista, essa aproximação entre antropólogos da ciência e etnólogos pode ser relacionada à consolidação de um campo de pesquisa interdisciplinar com características próprias.

Ainda que as pesquisas antropológicas voltadas para as ciências se espraiem por diferentes grupos e instituições brasileiras (Rohden; Monteiro, 2019), gostaríamos de focar aqui o movimento que emerge no contexto do Museu Nacional (UFRJ), entendendo-o como um marco relevante para o diálogo entre etnologia e antropologia da ciência ao qual nos referimos. Institucionalmente, esses encontros foram fomentados pelas reuniões do Grupo de Estudos de Antropologia da Ciência e da Tecnologia (GEACT/MN-UFRJ), do Núcleo das Transformações Indígenas (NuTI) e do Núcleo de Antropologia Simétrica (NAnSi/MN-UFRJ), que tiveram centralidade na elaboração da primeira Reunião de Antropologia da Ciência e da Tecnologia (ReACT), realizada em 2007 no Instituto de Filosofia e Ciências Sociais (IFCS) da Universidade Federal do Rio de Janeiro. Desde então, o diálogo com a etnologia indígena tem sido uma tônica importante em todas as Reuniões de Antropologia da Ciência e da Tecnologia, que acontecem bianualmente.

Na deriva deste movimento, propusemos - por ocasião da VII ReACT, em 2019 - o seminário temático Conexões transversais entre a antropologia da ciência e tecno- 
logia e a etnologia. Nele pretendíamos aprofundar as discussões sobre como essas conexões vêm sendo exploradas na antropologia brasileira na última década, a partir de diálogos interessantes (e interessados) entre campos de conhecimento tradicionalmente separados.

Entendemos que esses diálogos remetem a uma crítica que vem sendo elaborada desde pelo menos os anos 1990, dirigida aos chamados "grandes divisores", em particular à oposição canônica entre natureza e cultura que marca o pensamento antropológico. Uma crítica que remete aos autores que referenciam a consolidação de um campo emergente de estudos na antropologia brasileira, entre os quais Eduardo Viveiros de Castro, Manuela Carneiro da Cunha, Mauro Almeida, Bruno Latour, Tim Ingold, Donna Haraway, Marilyn Strathern, Philippe Descola, Isabelle Stengers, entre outros.

A antropologia social, em sua prática teórica e descritiva, teve como objeto de estudo, afinal, o fenômeno humano, definido nos termos daquilo que chamamos ora de "cultura", ora de "sociedade". A ordem da natureza ou dos fenômenos biológicos, entendida como passiva e destituída de qualquer forma de agência, funciona neste caso para definir, por contraste, os objetos de interesse das ciências sociais. Em uma ótica nitidamente representacionalista, as entidades não-humanas ficam reduzidas, assim, a partes do ambiente para ou do humano. A política entendida em termos de acordos ou contratos entre seres humanos tinha como pano de fundo uma natureza regida por leis mecânicas e fixas. As fronteiras disciplinares, nesse caso, correm sempre o risco de reproduzir a assimetria constitutiva, ou constitucional, a partir da qual Bruno Latour (2005) caracterizou a modernidade. De um lado, a concepção da ciência moderna como um saber acabado e final sobre o mundo tende a desprezar tudo aquilo que provém de protocolos alternativos. De outro, a ideia de que o saber tradicional é um patrimônio homogêneo e parado no tempo - e não um processo dinâmico - tende a reduzi-lo ao campo das representações ou das crenças.

Ao enunciar sua crítica a uma suposta modernidade, que mantém oficialmente tudo separado ou bem do lado da cultura ou bem do lado da natureza, mas que oficiosamente prolifera entidades híbridas de natureza-cultura, Latour tem em vista a tese de Descola (1996) entre os Achuar (povo ameríndio que habita a Amazônia equatoriana), e que permitiu ao etnólogo revisitar a ideia de animismo para questionar a suposta universalidade da oposição entre natureza e cultura. De certo modo, a antropologia simétrica latouriana tem uma dependência dos estudos etnológicos daqueles povos ditos não-modernos.

Até agora apontamos para um dos movimentos da antropologia da ciência praticada no Brasil em relação a uma das subáreas do conhecimento antropológico como uma forma possível de repensar e refazer a antropologia, e não como um nicho desse conhecimento tradicionalmente complementado por suas especialidades (da "política", da "religião", do "gênero", por exemplo). Entretanto a compartimentalização desse conhecimento em função de seus objetos de estudo - herdada da invenção das ciências modernas - gerou híbridos, como a antropologia da ciência, que agiram por inverter o sentido das reflexões costumeiramen- 
te sobrepostas às "outras epistemologias". Entendemos que a mesma inspiração e dinâmica podem ser percebidas em outras vertentes da etnologia brasileira contemporânea, em especial aquela tocada pelos princípios e efeitos da "virada ontológica”, notabilizada a partir dos primeiros anos do século XXI (Holbraad; Pedersen, 2017; Viveiros de Castro, 2014).

Contudo, essa "virada" está longe de se restringir à antropologia e, de forma semelhante, tem afetado profundamente os chamados "estudos sociais da ciência". A antropologia da ciência também precisou se conectar com esse campo previamente povoado por filósofos, historiadores e sociólogos, e sua contribuição tem sido a de chamar a atenção para os aspectos situados e parciais (Haraway, 1988) da produção de conhecimento. Ainda que possuíssem uma composição bastante plural, entretanto, os estudos sociais da ciência inadvertidamente preservavam, em grande parte, um certo impulso em reproduzir o eixo universalista de ciência moderna, tendendo a buscar respostas gerais para problemas locais. Perdia-se, com isso, a oportunidade de incorporação de reflexividades provenientes do contato com mundos outros, cujos representantes atualmente habitam também o "mundo da academia".

O fato é que os estudos sociais da ciência tiveram na controvérsia sobre quem estaria autorizado a falar "em nome da Ciência" um de seus marcos fundacionais: de um lado, os que se valiam do conhecimento direto obtido nas bancadas dos laboratórios, de outro, os que abordavam a prática científica como um fenômeno social. Mesmo que esse dispositivo dualista, que inspirou as chamadas "guerras da ciência", não seja tão evidente, atualmente ainda persiste certo mal-estar metodológico quando o caso deixa de ser "pensar sobre" as ciências e cientistas e passa a ser "pensar com" essas outras ciências, permitindo que os estudos sociais da ciência sejam transpassados também pelos problemas que tocam os cientistas (Stengers, 2002; Latour, 2017).

Esse último movimento, bastante sutil e sofisticado, é de difícil apreensão até mesmo para as perspectivas que apontavam para os imperativos políticos, sociais e culturais, ou seja, aqueles que envolvem as ditas "condições externas" de produção científica. Sob um viés ontológico, os tais "fatores externos" passam a ser elementos intrínsecos que revelam projetos de conhecimento sobre os quais é impossível dissociar o impulso mobilizador da prática científica dos seus efeitos. As marcas e as circunstâncias da produção de conhecimento são tão concretas e reais quanto as agências de seus produtos sociedade afora.

Dentro dessa perspectiva, uma vertente que tem obtido adesão - tanto nos estudos sociais da ciência quanto na antropologia brasileira em geral - nas duas últimas décadas é a chamada "antropologia simétrica". Uma tendência que se notabilizou através da obra do filósofo/antropólogo das ciências Bruno Latour, mas que remonta aos trabalhos de autores como David Bloor, Michel Callon, dentre outros associados à Teoria Ator-Rede. Resumida aos três princípios de simetria (Latour, 2004), a antropologia simétrica efetiva-se ao: considerar de interesse simétrico o resultado do conhecimento sem distinguir a priori sua "verdade" e "falsidade"; não separar, de antemão, actantes humanos e não-humanos; e não 
privilegiar as explicações dos "modernos" em detrimento às dos "não-modernos".

Se os dois primeiros enunciados parecem ter sido incorporados gradativamente pelos antropólogos e pesquisadores de CTS (Ciência, Tecnologia e Sociedade) brasileiros às suas agendas e protocolos de pesquisa, o mesmo não se pode dizer do último princípio. É significativo que esses estudos situados na América Latina, marcada pelo avanço do capitalismo tardio e definida dentro do conceito de modernidade periférica, não explorem tanto os diálogos simétricos entre as diversas formas de produção de conhecimento aqui presentes. A tentativa de simetria entre conhecimentos modernos e não modernos não é frustrada justamente em virtude da aproximação entre a antropologia da ciência e a etnologia de povos tradicionais. Mais do que um esforço de compreensão mútua, essa aproximação - entre alternativas modernas e não modernas - pressupõe levar a sério uma antropologia simétrica inovadora, instigante e eticamente valorada.

\section{Da Etnologia Ameríndia à Antropologia da Ciência}

Visto desde a etnologia, esse encontro pode ser ancorado em um movimento que envolve ao menos dois eixos de pesquisa consolidados no escopo da etnologia das Terras Baixas da América do Sul, a saber: de um lado, os estudos sobre conhecimentos tradicionais; de outro, aqueles sobre cosmologias indígenas. Esses dois caminhos culminam, atualmente, em um encontro entre perspectivas científicas e indígenas que é impelido pelo colapso ambiental que vivemos - antropoceno, capitaloceno ou plantationoceno (Haraway, 2016), a depender do estatuto de existência que queremos dar à crise.

De um lado, os estudos de cosmologia, tendo como nome de referência Eduardo Viveiros de Castro, estabelecem um diálogo direto com a filosofia ocidental, na medida em que o pensamento de povos ameríndios sobre o cosmo é alçado ao mesmo patamar reflexivo de nossos grandes pensadores. De outro lado, Mauro Almeida e Manuela Carneiro da Cunha são importantes referências nos estudos sobre conhecimentos tradicionais acerca do meio ambiente, algo que compõe e conversa com disciplinas das grandes áreas das ciências naturais. Pensando em obras, de um lado temos Inconstância da alma selvagem (Viveiros de Castro, 2002) e de outro, Enciclopédia da floresta (Carneiro da Cunha; Almeida, 2002).

Diante desses dois eixos dos estudos de etnologia ameríndia, a obra $O$ pensamento selvagem, de Lévi-Strauss (1997), apresenta-se como articular e abre para possíveis conexões com os estudos de ciência. Algo que está presente na entrevista de Manuela Carneiro da Cunha e Mauro Almeida que é parte desse dossiê.

O pensamento selvagem, de Lévi-Strauss, já havia antecipado, de certa forma, o problema em foco neste dossiê, ao propor um movimento de equiparação entre Nós e Eles muito antes que a noção de simetria fosse cunhada por Latour. Ao encarar a tarefa de tirar o pensamento de povos ditos primitivos do lócus de irracionalidade e do reducionismo utilitário em que havia sido colocado, Lévi-Strauss afirma a qualidade lógica e ilumina os procedimentos minuciosos de investigação e reflexão de diferentes povos ao redor do mundo. Referidas, em algumas passagens, como "dois tipos de conhecimento científico", essas formas de conhecimen- 
to não se distinguem pela qualidade e racionalidade, mas pelo tipo de material com que operam: um muito próximo das qualidades sensíveis que, à maneira de um bricoleur, trabalha com signos; outro que se distancia do concreto por meio de conceitos.

O grande movimento de simetrização realizado pelo autor nos parece ser a não reificação desses dois grandes modos de conhecimento a conjuntos sociológicos delimitados, tais como o Ocidente e os outros. Segundo o mestre estruturalista, a arte seria um campo de "pensamento selvagem" dentro da sociedade ocidental. Além disso, mesmo dentro do campo das ciências modernas, como na química, por exemplo, Lévi-Strauss encontra elementos da "ciência do concreto", constituída a partir de perceptos e não de conceitos. Estamos fora, portanto, de tipologias e diante de procedimento de conhecer e pensar distintos que devem ser tratados pelo analista de modo similar. Essa parece ser uma atitude fundante das possibilidades de diálogos transversais entre etnologia e antropologia da ciência, que abre caminho para uma série de desdobramentos na antropologia contemporânea.

Ainda que seja possível desenhar um esquema temporal de como a etnologia (amazônica, em especial) dialoga com conhecimentos científicos, atualmente há um número crescente de trabalhos (Garcia, 2018; Morim de Lima, 2017; Pitrou, 2017; Cabral de Oliveira, 2012 e 2020; Vander Velden, 2018; Almeida, 2013; entre outros) que buscam realizar uma mirada cruzada, onde os conhecimentos científicos figuram lado a lado com os pensamentos indígenas e de outros povos minoritários. Trata-se de um esforço reflexivo que parte dos problemas teórico-metodológicos da Antropologia da Ciência e de um esforço de simetria, para desestabilizar o polo do Estado e da Ciência. Os saberes científicos não são mais o dado, mas elementos que se prestam a uma análise agora afetada por saberes outros, uma vez que o ideal de pureza e objetividade universal de uma ciência oficial (ou de uma ciência com C maiúsculo, para falar com Stengers, 2017) é amplamente problematizado. Tal empreendimento, que vem sendo arriscado em diferentes vertentes, tenta tecer conexões parciais entre esses universos distintos, e dar conta de temas como o mau encontro entre povos tradicionais e os grandes empreendimentos marcados pelo Estado e pelo Mercado; ou as colaborações científicas com comunidades tradicionais; ou estabelecem uma conversa com a biologia com o intuito de dar outro estatuto aos organismos não-humanos na etnografia.

Nessa seara, merece destaque, por fim, a entrada crescente de indígenas e quilombolas na pós-graduação (Barreto, 2013; Mehinaku, 2010; Luciano, 2006; entre outros), bem como as publicações de livros de grandes pensadores desses povos (Krenak, 2017; Kopenawa; Albert, 2015; Santos, 2015), atores que passam a refletir de uma outra perspectiva sobre esse alinhamento entre ciência, modernidade e branquitude ocidental. Configura-se assim um cenário teórico-metodológico-político potente e em franca elaboração, a partir do qual se evidenciam pontes ou passagens possíveis entre o pensamento científico contemporâneo e o pensamento de povos e culturas que de fato nunca conceberam o humano como um domínio separado e oposto àquele da natureza. 


\section{A Composição do Dossiê}

Essas seriam, em linhas gerais, as questões que contextualizam, de alguma forma, o presente dossiê. Ele vem composto por uma entrevista, oito artigos e um ensaio bibliográfico. Todos estes textos apresentam múltiplas respostas à provocação de refletir sobre as conexões transversais entre etnologia e antropologia da ciência e como etnografar as relações complicadas entre natureza e cultura, que já não se sustentam mais como domínios apartados, assim como a ciência não se mantém como conhecimento de autoridade exclusiva sobre o real

O primeiro deles, de Kauã Vasconcelos e Felipe Süssekind, se refere a processos entendidos como transformações. Os autores elaboram uma cartografia de algumas das formas nas quais os botos se manifestam na Amazônia brasileira, tendo como ponto de partida um experimento de pesquisa de campo colaborativa promovido pelo Instituto Bicho D'água, que trabalha com mamíferos aquáticos na Ilha do Marajó (PA). Partindo desta experiência, assim como de uma revisão bibliográfica ampla sobre o tema, o artigo propõe conexões transversais entre diferentes campos de conhecimento, ligando a conservação de espécies ameaçadas aos mitos do boto sedutor e ao mundo sobrenatural da Encantaria amazônica. Os modos como os botos se manifestam nesses diferentes campos são entendidos, nesse caso, como elementos em um conjunto de transformações que não são redutíveis entre si.

A experiência etnográfica de Bethânia Gabrielle dos Santos e Teresa Braga Branquinho no Espinhaço Meridional (MG) descreve, por sua vez, o modo como um grupo de plantas conhecidas como sempre-vivas agencia associações entre humanos e não-humanos. Em uma abordagem ligada à teoria-ator-rede (ANT), que propicia diálogos entre ontologias e coletivos heterogêneos, o artigo investiga a rede sociotécnica das sempre-vivas e a controvérsia envolvendo políticas ambientais e comunidades de apanhadores(as) de sempre-vivas, as quais reivindicam o direito de reprodução de suas práticas como extrativistas.

No terceiro artigo do dossiê, Hugo Maximino Camarinha apresenta os desdobramentos de sua pesquisa sobre música e xamanismo Ka'apor, realizada na Terra Indígena do Alto Turiaçu (MA). A experimentação, que o autor caracteriza como uma busca por uma "etnomusicologia de multiespécies", parte de narrativas e mitos de criação que descrevem como as pessoas surgiram do tronco de algumas árvores. A ideia de agência multiespecífica se contrapõe, neste caso, à concepção da gênese dos ecossistemas florestais pela mão única dos coletivos humanos. Com isso, o artigo questiona alguns dos paradigmas acionados pela Ecologia Histórica, vinculados ao antropocentrismo e à centralidade da ação humana na transformação da paisagem e do clima.

O trabalho seguinte, de Leon Terci Goulart, surge a partir da participação do autor no Projeto Yaripo, um projeto de ecoturismo de base comunitária que envolve a visitação à Terra Indígena Yanomami e ao Parque Nacional do Pico da Neblina. A associação, no contexto do projeto, entre uma nova fonte de renda, uma proposta de combate ao garimpo ilegal e um meio de "proteger a natureza e a floresta" propicia uma reflexão sobre o modo como algumas categorias do 
discurso ambientalista são acionadas pelos Yanomami. O autor mostra, nesse sentido, que conceitos como "natureza", "floresta" e "território" podem ser lidos e mobilizar conexões entre pressupostos ontológicos distintos. $\mathrm{O}$ artigo se volta, em particular, para o modo como a noção de urihi, a floresta yanomami, descrita em termos de "um espaço cosmopolítico habitado por subjetividades não humanas" surge na elaboração do projeto de ecoturismo como elemento fundamental para se pensarem as implicações do trânsito pelos lugares destinados à visitação.

Tendo como ponto de partida uma pesquisa colaborativa entre pesquisadores indígenas e não indígenas, cantores e mestres rituais krahô, o artigo de Ana Gabriela Morim de Lima, Creuza Prumkwyj Krahô e Veronica Aldé é definido pelas autoras como "uma experiência de registro, documentação e qualificação de narrativas míticas e pessoais, cantos e performances associados aos rituais do milho". As histórias e os cantos, no caso, estão ligados ao ciclo da vida do milho, desde o plantio, passando pelos resguardos seguidos pelos agricultores, até a colheita. Em uma leitura etnográfica atenta, as negociações contínuas entre os diversos seres humanos e não-humanos que coabitam no Cerrado são descritas em termos que vão muito além da importância alimentar para os agricultores krahô, revelando conexões entre práticas de cultivo, saberes rituais, mitos e experiências.

O artigo de Julia Sá Earp de Castro, sexto na nossa série, aborda questões contemporâneas da sociedade Mẽbêngokre-Kayapó, a partir de uma pesquisa de campo sobre a Casa de Costura idealizada por Tuíre Kayapó na localidade de Kaprãnkrere, assim como em relatos e histórias contadas sobre a origem destas vestimentas no território indígena. Os vestidos utilizados pelas mulheres deste povo propiciam reflexões sobre pontes construídas pelas mulheres mẽbêngôkre entre seus mundos e o dos brancos, ligadas à manipulação de substâncias materiais e imateriais que se constituem como estratégias estéticas e políticas de construção de seus corpos.

Tendo como pano de fundo a criação e a reprodução das florestas de castanhais (Bertholletia excelsa), Igor Scaramuzzi aborda, na sequência, as concepções e os conhecimentos dos quilombolas habitantes do Alto Trombetas, município de Oriximiná (PA), em diálogo com as hipóteses científicas formuladas por pesquisadores de diferentes áreas do conhecimento sobre este tema. A pesquisa etnográfica conduzida pelo autor mostra como as concepções quilombolas incorporam elementos dos debates científicos sem, contudo, tomarem como pressupostos o protagonismo humano ou a separação entre os domínios da natureza e da cultura que pautam esses debates. Prescindindo de uma concepção antropocêntrica da natureza, os conhecimentos quilombolas a respeito das florestas de castanhais apontam para o que Scaramuzzi caracteriza como "uma forma de socialidade não hierárquica, baseada, na parceria e na ajuda mútua entre humanos e não humanos".

O último artigo da série, de Eleandra Raquel da Silva Koch e Vanessa Flores dos Santos, foi elaborado a partir de um trabalho etnográfico realizado no bojo do processo administrativo de regularização fundiária do quilombo da Costa da Lagoa, às margens da Lagoa Capivari (RS). Frente a projetos voltados para uma suposta funcionalidade e "desenvolvimento" regional, as autoras apresentam práticas de 
conhecimentos que mobilizam as águas e entidades não-humanas com as quais os quilombolas compartilham seu território ancestral. Elas nos mostram que essas práticas remetem a importantes ciclos de vida da coletividade negra - como as festas de Nossa Senhora de Navegantes e os batismos "em casa" -, ligados a processos que são caracterizados em termos de (re)existências.

Contamos ainda com o ensaio bibliográfico de Gabriel Holliver, que tece importantes comentários acerca dos artigos presentes no livro recentemente traduzido de Anna Tsing - Viver nas ruínas: paisagens multiespécies no Antropoceno. Anna Tsing é, sem dúvida, uma autora central para se pensar sobre como transladar entre diferentes regimes de conhecimento e, desta forma, se operacionalizarem discussões entre o campo da etnologia e dos estudos de ciência. $\mathrm{O}$ ensaio oferece um panorama sobre os principais conceitos e linhas de força que atravessam o pensamento da autora, apresentando também suas criticas à reificação do excepcionalismo humano na antropologia, para, por fim, esboçar possíveis diálogos entre suas reflexões e a antropologia produzida no Brasil.

Para compor o dossiê, trazemos ainda uma entrevista com Manuela Carneiro da Cunha e Mauro Almeida provocada pela temática em torno da qual o dossiê foi organizado, a saber, Conexões transversais entre Antropologia da Ciência e da Etnologia, e que nos traz não só uma perspectiva histórica do campo na antropologia, como aponta para possíveis desdobramentos e campos de investigação e atuação.

Boa leitura! 


\section{Referências}

ALMEIDA, Mauro. Caipora e outros conflitos ontológicos. R@U - Revista de Antropologia da UFSCar, v. 5, n. 1, p. 7-28, jan.-jun. 2013.

BARRETO, João Paulo Lima. Wai-Mahsã: peixes e humanos. Um ensaio de Antropologia Indígena. Manaus, Amazonas. 2013. Dissertação (Mestrado) - Universidade Federal do Amazonas, Manaus, 2013.

CABRAL DE OLIVEIRA, Joana. "Vocês sabem porque vocês viram!": reflexão sobre modos de autoridade do conhecimento. Revista de Antropologia, v. 55, n. 1, p. 51-74, jan.-jun. 2012.

CABRAL DE OLIVEIRA, Joana. As vicissitudes do matar. Conflitos ontológicos em um estudo sobre leishmaniose tegumentar americana na TI Wajãpi. Horizontes antropológicos, v. 26, n. 57, p. 177-205, 2020.

CABRAL DE OLIVEIRA, Joana. Entre plantas e palavras: modos de constituição de saberes entre os Wajãpi (AP). Tese (Doutorado em Antropologia Social) - Universidade de São Paulo, São Paulo, 2012.

CALHEIROS, Orlando. As transformações do Leviatã: praxiografia de um projeto de cetologia. Dissertação (Mestrado em Antropologia Social) - Universidade Federal do Rio de Janeiro, Rio de Janeiro, 2009.

CARNEIRO DA CUNHA, Manuela; ALMEIDA, Mauro Barbosa de (Orgs.). Enciclopédia da Floresta: o Alto Juruá - práticas e conhecimentos das populações. São Paulo: Cia. das Letras, 2002.

CARNEIRO DA CUNHA, Manuela; ALMEIDA, Mauro Barbosa de. Populações tradicionais e conservação ambiental. In: CARNEIRO DA CUNHA, Manuela. Cultura com aspas e outros ensaios. São Paulo: Cosac Naify, 2009.

DESCOLA, Philippe. La selva culta. Quito: Abya-Yala, 1996.

ESTORNIOLO, Milena. Laboratórios na floresta: os Baniwa, os peixes e a piscicultura no Alto Rio Negro. Dissertação (Mestrado em Antropologia Social) - Universidade de São Paulo, São Paulo, SP.

GARCIA, Uirá. Macacos também choram. Revista do Instituto de Estudos Brasileiros, n. 69, p. 179-204, 2018.

HARAWAY, Donna. Situated knowledges: the science question in feminism and the privilege of partial perspective. Feminist Studies, v. 14, n. 3, p. 575-599, 1988.

HOLBRAAD, Martin; PEDERSEN, Morten. The ontological turn: an anthropological exposition. Cambridge: Cambridge University Press, 2017.

KOPENAWA, Davi; ALBERT, Bruce. A queda do céu: palavras de um xamã yanomami. Trad. de Beatriz Perrone-Moisés; prefácio de Eduardo Viveiros de Castro. São Paulo: Companhia das Letras, 2015.

KRENAK, Ailton. Ailton Krenak. Rio de Janeiro: Azougue Editorial, 2017.

LATOUR, Bruno. A esperança de Pandora: ensaios sobre a realidade dos estudos científicos. São Paulo: Ed. Unesp, 2017 [1999].

LATOUR, Bruno. Jamais fomos modernos: ensaios de Antropologia Simétrica. São Paulo: Editora 34, 2005 [1991].

LÉVI-STRAUSS, Claude. O pensamento selvagem. Campinas: Papirus,1997 [1962].

LUCIANO, Gersem José dos Santos. Projeto é como branco trabalha: as lideranças que 
se virem para ensinar. Dissertação (Mestrado em Antropologia) - Universidade de Brasília, Brasília, 2006.

MARRAS, Stelio. Recinto e evolução: capítulos de antropologia da ciência e da modernidade. Tese (Doutorado em Antropologia Social) - Universidade de São Paulo, São Paulo, 2009.

MEHINAKU, Mutua. Tetsualü: pluralismo de línguas e pessoas no Alto Xingu. Dissertação (Mestrado em Antropologia Social) - Universidade Federal do Rio de Janeiro, Rio de Janeiro, 2010.

MORIM DE LIMA, Ana Gabriela. A cultura da batata doce: cultivo, parentesco e ritual entre os Krahô. Mana, v. 23, n. 2, p. 455-490, 2017.

PITROU, Perig. Life form and form of life whiten an Agentive configuration. Current Anthropology, v. 58, n. 3, p. 360-380, 2017.

ROHDEN, Fabiola; MONTEIRO, Marko Synésio Alves. Para além da ciência e do anthropos: deslocamentos da antropologia da ciência e da tecnologia no Brasil. Revista Brasileira de Informação Bibliográfica em Ciências Sociais, São Paulo, n. 89, p. 1-33, 2019.

SÁ, Guilherme José da Silva e. No mesmo galho: ciência, natureza e cultura nas relações entre primatólogos e primatas. Tese (Doutorado em Antropologia Social) - Universidade Federal do Rio de Janeiro, Rio de Janeiro, 2006.

SANTOS, Antonio Bispo dos. Colonização, Quilombos: modos e significados. Brasília: INCTI/UnB, 2015.

STENGERS, Isabelle. A invenção das ciências modernas. São Paulo: Editora 34, 2002 [1993].

STENGERS, Isabelle. Reativar o animismo. Belo Horizonte: Chão de Feira, 2017.

SÜSSEKIND, Felipe. O rastro da onça: etnografia de um projeto de conservação em fazendas de gado do Pantanal Sul. Tese (Doutorado em Antropologia Social) -Universidade Federal do Rio de Janeiro, Rio de Janeiro, 2010.

VANDER VELDEN, Felipe. Vocês, brancos, são peixes: sobre os equívocos na pesca e na piscicultura entre os Karitiana, Rondônia. R@U - Revista de Antropologia Social dos Alunos do PPGAS-UFSCAR, v. 10, p. 164-194, 2018.

VIVEIROS DE CASTRO, Eduardo. A inconstância da alma selvagem. São Paulo: Cosac Naify, 2002.

VIVEIROS DE CASTRO, Eduardo. Who is afraid of the ontological wolf? Some comments on an ongoing anthropological debate. CUSAS Annual Marilyn Strathern Lecture, 30 May. 2014.

WALFORD, Antonia. Cumplicidade científica e etnográfica: explorando o LBA. Dissertação (Mestrado em Antropologia Social) - Universidade Federal do Rio de Janeiro, Rio de Janeiro, 2008. 